\title{
EESTI-LÄTI KOODIKOPEERIMINE: ADAPTSIOON JA IMPOSITSIOON
}

\author{
Elīna Joenurma \\ Tallinna ülikool
}

Ülevaade. Artiklis käsitlen kontaktist johtuvaid keelemuutusi eesti-läti kakskeelse isiku keelekasutuses sotsiolingvistilisest lähenemisnurgast. Artikkel tugineb minu Tallinna Ülikoolis 2016. aastal kaitstud magistritööle „Eesti-läti kakskeelse isiku keelekasutus“. Keeleainestiku kogusin välitöö käigus ning kogutud materjali analüüsimiseks kasutan Lars Johansoni koodikopeerimise mudelit, kuna see on paindlik ning käsitleb sõnavaras ja grammatikas toimuvat ühtses terminoloogias. Samuti saab seda mudelit rakendada kopeerimise uurimiseks mõlemas suunas, nii adaptsioon K2 > K1 kui ka impositsioon K1 > K2. Kuna sellist eesti-läti kakskeelsust ei ole varem uuritud, ei ole võimalik sõnastada ka väga konkreetseid hüpoteese. Küll aga võib eeldada varasemate kontaktlingvistika tööde põhjal, et ülekaalus on täielikud koopiad ning valikulisi ja segakoopiaid on täielike koopiatega võrreldes vähe.

Märksõnad: koodikopeerimine, adaptsioon, impositsioon, eesti, läti

\section{Sissejuhatus}

Eestlasi ja lätlasi kui naabreid seob pikk, aastasadu kestnud ühine ajalugu, esiajaloolised kokkupuuted ulatuvad aga mitme aastatuhande taha (Vaba 2010a: 361). Ka läti-eesti keelekontaktidel on pikk ajalugu ning mõlemas keeles on selle jälgi. Seni on rohkem uuritud eesti-läti ja läti-eesti vastastikust sõnavara laenamist (Vaba 1997, 2010a, 2010b). Näiteks toob Vaba (2010b: 210) välja, et eesti lätilaenulises sõnavaras domineerib koduse eluga seotud sõnavara (näiteks joogid-söögid, rõivad). Samuti on rohkem tähelepanu pööratud eestlaste ajaloole Lätis ja lätlaste ajaloole Eestis ning eestlaste ja lätlaste elulugudele (Mela 2007, 2013, Utno 2007, 2008). 
Keelekontaktid ei piirdu ainult sõnavara laenamisega ning sünkrooniliselt ei ole eesti-läti kakskeelsust seni uuritud. Eesti-läti kakskeelsusest ei saa rääkida kui makrotasandil levinud nähtusest, küll aga esineb niisugust kakskeelsust individuaalselt ja segaperedes.

Minu eesmärk oli uurida kontaktist johtuvaid keelemuutusi eesti-läti kakskeelse isiku keelekasutuses sotsiolingvistilisest lähenemisnurgast. Eesti-läti kakskeelse kõne uurimiseks püstitasin kolm uurimisküsimust.

1. Kas koodikopeerimine toimub mõlema keele suunas?

2. Milliseid koopialiike keelejuhi kõnes esineb?

3. Kui koodikopeerimine on mõlemapoolne, kas koopiate liigid erinevad olenevalt kopeerimissuunast?

Püstitatud uurimisküsimustele vastuste leidmiseks kasutan empiirilise keelematerjali analüüsimiseks Lars Johansoni koodikopeerimise mudelit, kuna see on paindlik ning käsitleb sõnavaras ja grammatikas toimuvat ühtses terminoloogias (Joenurma 2016: 4-6).

Kuna sellist materjali ei ole varem uuritud, ei ole võimalik sõnastada väga konkreetseid hüpoteese. Küll aga eeldan varasemate kontaktlingvistiliste tööde põhjal, (näiteks Roosileht 2013, Igav 2013, Paljasma 2012, Vaba 2010), et ülekaalus on täielikud koopiad ning valikulisi ja segakoopiad on täielike koopiatega võrreldes vähe.

Artikkel koosneb kuuest osast. Esimeses osas annan ülevaate andmete kogumisest ning keelejuhi taustast. Teises osas tutvustan Lars Johansoni koodikopeerimise mudelit ja selle mudeli koopialiike. Kolmandas ja neljandas osas käsitlen adaptsiooni ja impositsiooni. Uuritud materjalis esines ka koodivahetust, millest annan lühikese ülevaate viiendas osas. Artikli kuuendas osas esitan ülevaate uurimuse tulemustest.

\section{Andmed ja keelejuht}

Minu eesmärk oli uurida kas Eestis elava lätlase või Lätis elava eestlase kakskeelset keelekasutust. Keelejuhi otsimisel oli oluline kriteerium, et ta oleks elanud ühes või teises riigis vähemalt nii kaua, et 
räägiks soravalt nii läti kui ka eesti keelt. Keelejuht ei pidanud tingimata olema eesti-läti kakskeelne keelekasutaja lapsepõlvest saati (Joenurma 2016: 8).

Kuna keelejuhi leidmine ei olnud väga kerge, siis otsustasin töötada keelejuhiga, kelle kohta oli teada, et ta on kakskeelne, ja kes oli intervjueerimisega nõus. Keelematerjali kogusin välitöö käigus, intervjueerides 2013. aasta veebruaris ning 2015. aastal 14. juunist kuni 20. septembrini Lätis Ainaži linnas elavat 1935. aastal sündinud prouat. Keelejuhi esimene abikaasa oli eestlane ja nad elasid Eestis. Tema mõlema lapse emakeel on eesti keel, kuna nad on Eestis elanud ja koolis käinud. Teine abikaasa oli tal Läti eestlane ning keelejuht kolis 40-aastasena Lätti. Nende kodune keel oli eesti keel, aga nad oskasid ka läti keelt. Oluline on see, et keelejuht on omandanud keelekuju, mida kasutatakse tema vahetus ümbruses. Keelejuhti ei ole kunagi õpetatud õpiku järgi, vaid ta on läti keelt õppinud tööl ning kohalike elanikega suheldes. Seega läti keele variant, mida keelejuht valdab, on kohalik murre, mis kuulub liivipäraste murrete hulka (Tāmnieku dialekts). Ei saa küll väita, et Ainažis räägitakse ainult murdes, kuid see murre ei ole kadunud. Keelejuht oskab kindlasti passiivselt ka läti kirjakeelt, kuna ta loeb Läti ajalehti ja ajakirju (Joenurma 2016: 10-12).

Intervjuusid viisin läbi nii eesti kui ka läti keeles. Intervjuusid lindistasin keelejuhi kodus ning ühe intervjuu pikkus oli 50-60 minutit. Kokku viisin läbi kaheksa intervjuud. Vestlust alustasin poolstruktureeritud intervjuuna, küsisin eluloolisi andmeid ja keelekasutustavade kohta. Sellele järgnes vabas vormis vestlus, mis oligi minu eesmärk, et koguda keeleainestikku, mis oleks lähedane argivestlusele ning võimaldaks koguda vajalikus mahus keeleainestikku. Lisaks kõne salvestamisele tegin ka märkmeid iga intervjuu kohta, näiteks millest me rääkisime, kuidas vestlus kujunes.

Vestlustes käsitlesime erinevaid teemasid. Rääkisime keelejuhi elust, tema Lätti elama asumisest, perekonnast, keelekasutusest perekonnas, tööst, reisimisest, tervisest, naabritest, argipäeva toimetamistest, poliitikast, kohalikest elanikest, sõbrannadest, 
sugulastest ja kassist, keda keelejuht peab perekonnaliikmeks ning väga oluliseks (Joenurma 2016: 12).

Välitööl peab alati arvesse võtma uuritava ja uurija omavahelisi suhteid. Näiteks mina ja keelejuht elame samas linnas ja tunneme kohalikku kultuuri ning inimesi, samuti oleme mõlemad eestiläti kakskeelsed keelekasutajad. Minu arvates aitas see kujundada intervjuud argivestluseks, kuna keelejuhil ja minul oli kerge vestlust suunata ja rääkida teemadest, millega oleme mõlemad tuttavad. Seega võib väita, et oli kergem saavutada püstitatud eesmärk ehk salvestada tavalist argivestlust. Kuigi alati peab arvesse võtma, et lindistamisel võib keelejuht oma keelekasutust muuta, tundub mulle siiski, et minu keelejuht ei pööranud lindistamisele väga suurt tähelepanu, kuid ma ei saa väita, et lindistamine ja minu juuresolek keelejuhi keelekasutust üldse ei mõjutanud (Joenurma 2016: 9-12).

\section{Koodikopeerimise mudel}

Koodikopeerimise mudelit on Eestis edukalt kasutatud ka varem. Lars Johansoni koodikopeerimise mudeli abil on eesti-vene keelekontakte uurinud Anna Verschik (2006, 2007, 2008, 2010, 2014), samuti on mudelit rakendanud Kristiina Praakli (2009), Reet Igav (2013), Veronika Paljasma (2012), Helin Roosileht (2013), Marja Vaba (2010).

Koodikopeerimise mudeli põhimõte on keele elementide, näiteks leksikaalsete üksuste ja grammatiliste mallide, kopeerimine ühest keelest teise. Keelt, mille elemente sisestatakse, nimetatakse mudelkoodiks ning keelt, millesse elemente sisestatakse, nimetatakse põhikoodiks. Koodikopeerimise mudelis eristab Johanson täielikke koopiaid (global copy), valikulisi koopiaid (selective copy) ning segakoopiaid (mixed copy). Koopiatel võib olla nelja tüüpi omadusi - materiaalsed (hääldus, aktsent, rõhk ning intonatsioon), kombinatoorsed (sõnajärg, rektsioon, fraasi struktuur), semantilised (sõna või väljendi tähendus) ning sageduslikud (keeleelemendi esinemissagedus). Koopialiigid on omavahel seotud ning erinevad 
vaid kopeerimise mahu poolest. Kopeerida võib kas kõiki omadusi täies mahus või ainult osa omadusi (Johanson 2002: 288-292).

Täielik koopia koodikopeerimise mudelis tähendab, et mudelkoodi üksus kopeeritakse tervikuna, kaasa arvatud selle kõik materiaalsed, semantilised, kombinatoorsed ning sageduslikud omadused (Johanson 2002: 291-292). Valikuline koopia tähendab, et kopeeritakse üht või mitut, kuid mitte kõiki omadusi. Mudelkoodist kopeeritakse põhikoodi valikuliselt üksikuid materiaalseid, kombinatoorseid, semantilisi ja sageduslikke omadusi. Segakoopiad kombineerivad mõlemaid elemente nii mudelkoodist kui ka põhikoodist. Vähemalt üks element peab olema täielik koopia ja teine element on valikuline (Johanson 1999: 45).

Lars Johansoni koodikopeerimise mudeli valisin ka seetõttu, et seda on võimalik rakendada mõlemas kopeerimissuunas. Seega nimetab Johanson adaptsiooniks seda, kui kopeeritakse sotsiolingvistiliselt domineerivast keelest $\mathrm{B}$ domineeritavasse keelde $\mathrm{A}$, kus mudelkood toob muutusi põhikoodi. Impositsiooniks nimetab Johanson seda, kui kopeeritakse domineeritavast keelest A domineerivasse keelde B, kus põhikood toob muutusi mudelkoodi (Johanson 2002: 291).

Käesolevas artiklis on tegemist nii adaptsiooniga (K2 > K1 ehk läti keelest eesti keelde) kui ka impositsiooniga (K1 > K2 ehk eesti keelest läti keelde). Kuna aga keelejuht räägib soravalt mõlemat keelt ja kohati on koodikopeerimine üsna tihe, siis on keelte omandamise järjekord nummerdatud kronoloogiliselt (eesti keel on esimesena (K1) ja läti keel on teisena (K2) omandatud), aga ei kirjelda keeleoskustaset (Joenurma 2016: 18).

\section{Adaptsioon ehk kopeerimine läti keelest eesti keelde}

Täielikku kopeerimist soodustab sageli elemendi atraktiivsus. Mõned elemendid on atraktiivsemad kui teised, aga atraktiivsust ei saa vaadata kui üldist terminit, kuna see sõltub konkreetsest kontaktsituatsioonist (Backus, Verschik 2012: 134). Atraktiivsuse 
määravad keeleelemendi omadused, nagu spetsiifiline tähendus ehk semantiline spetsiifilisus. Näiteks läti keelest eesti keelde kopeerib keelejuht perekonnaga seotud sõnu, nagu läti $m a \bar{s} \bar{c} c a$, liivipärane murre māsica, eesti 'täditütar/onutütar', liivipärane murre $m a \bar{s}$, läti $m a ̄ s a$, eesti 'õde', läti mazdēls, eesti 'pojapoeg', liivipärane murre onkul, läti onkulis, eesti 'onu'. Perekonnaga seotud sõnade kopeerimist võib soodustada see, et keelejuht on palju rääkinud oma perekonnast läti keeles ning need on juba muutunud harjumuspärasteks sõnadeks nagu näidetes 1 ja 2 (Joenurma 2016: 28).

(1) Tegi māsica nime peale maja (murdes māsica, läti māsīca, eesti 'täditütar/onutütar')

(2) Mās helistab! (murdes mās, läti māsa, eesti ‘õde’)

Kopeerimist võivad soodustada ka sarnasused, näiteks sama sõnajärg, ühisest allikast pärit leksikaalsed elemendid, näiteks ühised võõrsõnad (Verschik 2007: 367, 2008: 90). Eesti ja läti keeles on palju laene ühisest allikast, nimelt saksa keele variantidest, kõige rohkem alamsaksa keelest (Joenurma 2016: 29).

Näites 3 esineb sõna korsten, mis on nii läti kui ka eesti keelde laenatud alamsaksa sõnast schorstēn. Läti kirjakeeles on sõna skurstenis, kuid keelejuhi kõnes on kadunud sõna lõpp -is.

(3) Skursten on ära.

(murdes skursten, läti skurstenis, eesti 'korsten’)

Näites 4 esineb sõna knapi 'napilt'. Sõna napp on laenatud alamsaksa sõnast $k n a p(p e)$. Mõlema sõna sarnasus võis kopeerimist soosida.

(4) Aga ta oli nii tulnud knapi (.) et oleks aeda ära noh (.) riivinud. (läti knapi, eesti 'napilt')

Keelejuhi kõnes esineb nimisõnade morfosüntaktiline integreerumine, mis ei toimu küll alati. Integreerumine tähendab mudelkoodi elementide kohandamist $\mathrm{K} 1$ fonoloogilise, morfoloogilise ning süntaktilise struktuuriga (Praakli 2009: 116). Näites 5 esineb sõna 
jauneid 'uusi'. Keelejuht räägib sugulasest, kes on talle riideid toonud. Ta nimetab toodud riideid kaltsudeks, kuna need on talle liiga suured. Läti nimisõna jaun- tüvele on keelejuht lisanud -e-, et saaks moodustada eesti keele mitmuse osastavat jaun-e-id. Läti kirjakeeles jaunas 'uued' on mitmuse nimetavas käändes. Diskursusmarkerist tur 'seal' kirjutan näites 8 .

(5) Sellel on ka tead tur (.) siia tõi mulle jauneid kaltsusid tead. (läti jaunas, eesti 'uued')

Kopeerimist ei ole alati võimalik selgitada. Näiteks tavaliselt öeldakse, et nn kinnised klassid, kuhu kuuluvad grammatilised sõnad, kaasa arvatud asesõna, ei ole hõlpsasti kopeeritavad, aga samas ei ole see ka võimatu (Backus, Verschik 2012). Näites 6 esineb määratlev asesõna abi divi 'mõlemad kaks'. Selle asesõna kopeerimist on raske seletada.

(6) Ta saatis selle (...) lapsed ära (..) ja siis me abi divi jõime.

(läti abi divi, eesti 'mõlemad kaks')

Samuti võib kopeerimise põhjus olla pragmaatiline olulisus. Kui mõni element on pragmaatiliselt oluline, näiteks väljendab kõneleja suhtumist või ütluste omavahelist suhet, siis on selle kopeerimine tõenäoline (Backus, Verschik 2012: 142). Sellised elemendid on diskursusmarkerid, mida kopeeritakse tavaliselt täielikult (Joenurma 2016: 22).

Yaron Matrase (2009: 193) järgi asuvad just diskursus-pragmaatilised sõnad laenatavuse hierarhia tipus. Küll aga kopeeritakse diskursusmarkereid vähe läti keelest eesti keelde. Diskursusmarkerite liigitamisel kasutan Suzanne Wertheimi (2003) klassifikatsiooni, mille järgi esineb keelejuhi kõnes rinnastav konjunktsioon ( $u n$ ' $j a$ ') näites 7, metakommentaar (adverb tur 'seal', asesõna kas 'mis') näites 8 ja hinnangusõna (adverb $n \bar{e}$ 'ei' ). Ei esinenud aga ühtegi suhtlusperformatiivi. See võib olla sellepärast, et kuna enamasti rääkis keelejuht ehk esines monoloog, siis suhtlussituatsioon ei eeldanudki suhtlusperformatiivide kasutamist (näiteks tere, head aega, tänan 
jne). Seega on suhtlusperformatiivide esinemine tingitud suhtlussituatsioonist (Joenurma 2016: 33). Näites 8 olevast sõnast jauneid kirjutasin näites 5 .

(7) Aga siis ta tuli ütlema et tüdrukud lapsed on haiged ja see jääb ära see jääb kas siis on teisipäev või kolmapäev un un panin uue selle tead.

(läti un, eesti 'ja')

(8) Sellel on ka tead tur (.) siia tõi mulle jauneid kaltsusid tead. (läti tur, eesti 'seal')

Valikulist kopeerimist esineb vähem kui täielikku kopeerimist ning kopeeritakse materiaalseid ja semantilisi omadusi. Näites 9 esineb sõna analīsid 'analüüsid' Läti keeles on sõna ainsuse nimetavas analize ning mitmuse nimetavas analizes sama tähendusega nagu eesti keeles 'analüüs', mis tähendab 'aine koostise osalist või täielikku kindlakstegemist'. Tüvi on tajutav analüüs- või analīz-. Eesti keeles oleks 'tehakse analüüse' mitmuse osastavas käändes, läti keeles taisa analizzes 'tehakse analüüsid' mitmuse nimetavas. Sõna on ühine internatsionalism, mis on mõlemas keeles sarnane, aga mitte identne. Eesti keeles kasutatakse küll mitmuse osastavat, aga läti keeles mitmuse nimetavat. Keelejuht kasutab tüve lätipärasel kujul, lisab eesti mitmuse osastava tunnuse -sid, aga mall on jälle läti oma (nimetav kääne). Seega esineb läti tüvi (ehk käändelõppu pole) ning eesti mitmuse nimetav: analīs-id. Siin on juhtum, kus sõnavara ja morfosüntaks ei ole selgelt eristatavad.

(9) Seal tehakse analīsid.

(läti analizes, eesti 'analüüsid')

Huvitaval kombel esinevad ka vahepealsed juhtumid ning on raske määrata, mis koopialiiki nad kuuluvad. Selliseid juhtumeid on ainult üksikuid. Näites 10 esineb sõna pruutgan tähendusega 'peigmees'. Eesti keelde on sõna pruut, läti brūte laenatud alamsaksa sõnast brūt ning läti keele brūtgāns, eesti 'peigmees' on laenatud alamsaksa sõnast brūdegam (Karulis 1992: 150). Eesti keeles tähendab pruut 
naist, aga läti keeles on brūtgāns mees. Sõnast brūdegam on see läti keeles mugandus. Materiaalne sarnasus soodustab kopeerimist, kuigi tähendus kummaski keeles erineb. Seega keelejuht kopeerib läti sõnakuju, kuna see on sarnane, aga tähendus on eesti oma.

(10) Ja tuleb jälle tagasi (...) tal on ka noh pruutgan tead (.) (läti brütgāns, eesti 'peigmees')

\section{Impositsioon ehk kopeerimine eesti keelest läti keelde}

Nagu juba eespool kirjutasin, ei integreerita täielikult kopeeritud nimisõnu alati morfosüntaktiliselt. Näiteks näites 11 esineb sõna nutitelefon. Läti kõnekeeles kasutatakse ka sõna smārtfons, mis on pärit inglise sõnast smartphone, aga läti kirjakeeles on viedtālrunis. Selles kõnesituatsioonis võib keelejuhi jaoks olla sõna nutitelefon atraktiivsem sõna, kuna tema perekonna suhtluskeel on eesti keel ja ta teab, millisest telefonist räägitakse. Võimalik on ka olukord, et keelejuht ei ole teadlik, kuidas sõna nutitelefon läti keeles on, kuna tal ei ole olnud lätikeelse sõnaga kokkupuudet. Sõna smārtfons on kasutusel olnud suhteliselt lühikest aega ja on võimalik, et sõna ei olegi keelejuhi sõnavaras. Läti keeles on rektsioon vajag + akusatiiv vajag nutitelefon-u. Ka to on akusatiiv. Siit on näha, et puudub ühildumine demonstratiivpronoomeni ja nimisõna vahel. Nutitelefon on jäetud nimetavasse käändesse ning morfosüntaktiline integratsioon puudub.

(11) Vajag to nutitelefon.

'Vaja seda nutitelefoni'

Näidetes 12 ja 13 esineb sõna käula. Sõna käula tähendab kõnekeeles 'väiksem, viletsam laev, alus, paat või auto; logu'. Näites 12 räägib keelejuht, millistes toidupoodides ta käib. Selles näites kasutab ta sõna käula tähenduses 'ratastel kott'. Kuna tal on raske liikuda ja ta ei saa raskeid asju tõsta, siis on talle ostetud ratastel kott, millega poes käia. 
(12) Tā, ka man tas käula būs atpakaļ, tad es var site iet.

'Siis, kui mul see käula on tagasi toodud, siis ma saan sinna minna'

Näites 13 kasutab keelejuht sõna käula 'auto' tähenduses. Keelejuht räägib, et poeg oli ostnud uue auto, aga et pojapoeg on nii pikk ja ta ei mahu väiksesse autosse sisse.

(13)Man brāls bij līdzi un sak: tāda maza käula viṇi ju netiks ieksa nemaz tur.

'Mul oli vend kaasas ja ta ütleb: nii väiksesse käulasse nad ei saa ju sisse üldse'

Nagu adaptsioonis kopeeritakse ka impositsioonis sarnaseid leksikaalseid elemente. Näites 14 esineb sõna poliitik. Läti keeles on vaste politikis. Küsin keelejuhi käest, mida ta arvab poliitikast. Keelejuht vastab naljatades, et ta on ise parem poliitik. Kuna sõnad on eesti ja läti keeles sarnased, tunnetab keelejuht, et läti keeles on natuke teistsugune sõna, ja lisab korrates sõnale poliitik läti meessoo tunnuse $-s$. Läti keeles on politikis (meessoost) / politike (naissoost).

(14) EJ: Kā ar politiku?

'Kuidas on poliitikaga?'

KJ: Es pats ir labaks poliitik

'mina olen ise parem poliitik'

EJ: [Naerab]

KJ: Poliitiks vien pḷāpašan ir noh.

'Poliitik üks lobisemine on noh'

Võrreldes adaptsiooniga, esineb impositsioonis rohkesti diskursusmarkereid. Diskursusmarkeritena esinevad alistav (et), rinnastav ( $\mathrm{ja}$ ) ning vastandav konjunktsioon (aga, või) näidetes 15 ja 16, metakommentaar ja deiksis ( $j u$, oota, oot-oot, vaata, vat, tead, noh), hinnangusõnad (ai jumal, ei, vääks, nurr, auh, uha-uha). Suhtlusperformatiive aga ei esine, kuna ilmselt vestlussituatsioon neid ei soodustanud. 
(15) Ja būt zinajusi aga tu nezin.

'Kui oleks teadnud aga sa ei tea

(16) Tas bij ari tas vien (.) dakter või kas tas tur bij un jā (.) jā un tā (.) atsakas un es parakst un viss.

'See oli ka üks arst või kes ta seal oli ja jaa ja nii keeldun ja ma allkirjastan ja kõik'

Näites 17 esineb partikkel oot-oot. Oota on justkui stoppmärk, millega võib sisse juhatada pausi, seletusküsimuse, kõrvaljärjendi või ka teemamuutuse (Keevallik 2001: 143). Keelejuht räägib enda maja omanikust ja mina küsin, kus maja omanik nüüd elab. Keelejuht võtab aega partikliga oot-oot ja kohe kordab sama läti keeles pagaid 'oota'. Selline kordamine annab talle rohkem mõtlemisaega.

(17) Oot-oot pagaid (.) uz Igauṇ robeža uz Igauṇi puse Latvija.

'Oot-oot oota Eesti piiril Eesti piiril Läti poolel'

Näites 18 esineb onomatopoeetiline sõna nurra. Keelejuhile on kass väga oluline ja kassiga räägib ta ainult eesti keeles. Näites räägib keelejuht, et ta oli haiglas ja kui ta koju tagasi tuli, siis oli kass väga rõõmus olnud ja kogu aeg keelejuhile sülle ja voodisse magama läinud. Läti keeles jäljendatakse kassi ketravat häälitsust murr-murr. Läti keeles on tegusõna murrāt 'nurruma' ning kaķis murrā 'kass nurrub’. Võimalik, et keelejuht lisas sõnale nurr lõpu - $a$ sõnast murrā.

(18) Sākuma, kad es nāk vairak nekas nebij, ka tikai klēpi guḷ man blakus un tikai nāk site un nurra, nurra.

'Alguses, kui ma tulin siis rohkem midagi muud ei olnud, et ainult magab süles mu kõrval ja ainult tuleb siia ja nurr-nurr'

Valikulisi koopiaid on kordades vähem kui täielikke koopiaid. Näites 19 esineb lätikeelses vestluses konjunktsioon või. Keelejuht kasutab või sellises funktsioonis, nagu seda eesti keeles ei kasutata. Läti keeles saab konjunktsiooniga vai moodustada küsilause, aga eesti keeles või niisuguses funktsioonis ei kasutata, vaid küsilauset alustab sõna kas. Keelejuht on võtnud eesti võ $i$ materiaalsed omadused, aga kasutab vastava läti keele konjunktsiooni funktsiooni. 
(19) Un mās tūlīt (.) mās arī bij klāt tur un un un ta pras või (.) või vini var maksat tas?

'Ja õde kohe tuli ja küsib kas ta saab ära maksta?'

Nii nagu valikulisi koopiaid on ka segakoopiaid vähem kui täielikke koopiaid. Näites 20 esineb segakoopia neerus vēz. Keelejuht räägib oma vennast, kellel oli neeruvähk. Läti keeles neerud on nieres ja vähk on vēzis ning läti keeles öeldakse haiguse kohta nieru vēzis nagu ka eesti keeles 'neeruvähk'. Keelejuht tunnetab, et läti keeles on eesti sõna neerud sarnane, ning annab pausiga endale mõtlemisaega ja proovib veel kahel korral leida õiget läti sõna. Keelejuht moodustab segakoopia, ühildades eesti neerus ja läti vēz.

(20) Un viṇi nomir vinim bij neer (...) neer vēz neerus vēz.

'Ja ta suri ja tal oli neeruvähk'

Ka impositsioonis esineb ebaselge juhtum, mille puhul on raske määrata, mis koopialiiki see kuulub. Näites 21 esineb sõna narret 'nerrot'. Eesti ja läti keelde on see laenatud kas alamsaksa keelest narre või saksa keelest narren. Eesti sõnast narrima ja läti sõnast nerrot on moodustatud sõna narret. Eesti tüvele narr- lisatakse läti kirjakeeles infinitiivi lõpp -ot, keelejuht on selle asemel aga kasutanud lõppu -et. Sõnaga durns mõtleb keelejuht 'loll'. Durn-am esineb daativis, mis on üks laialdasi liivipärase murde tunnuseid. Kirjakeeles on durnu akusatiivis.

(21) Durnam var narret.

'Lolli võib narrida'

\section{Koodivaheldus}

Johanson eristab oma mudelis koodikopeerimist ja koodivaheldust (code-alternation). Koodivaheldus tähendab selles mudelis terveid lõike teises koodis (näiteks osalauseid ja lauseid) (Johanson 1999: 39, 2002: 287).

Ka kogutud keeleainestikus esineb mõni koodivahelduse näide. Koodivaheldus esineb mõlema keele suunas nii lausesiseselt kui ka 
lauseväliselt. Ühel korral toimub koodivaheldus kolme keele vahel: läti, vene ja eesti. Keelejuhi kõnes esineb koodivaheldus sageli just kellegi refereerimisel.

Näites 22 on lätikeelne osa paksus kirjas. Selles näites esineb koodivaheldus lausesiseselt ning toimub kahe keele vaheldus: eestiläti-eesti. Selles näites räägib keelejuht eesti keeles oma kassist, kellega ta räg̈gib ainult eesti keeles. Siin on hästi tihe kopeerimine. Keelejuht hakkab rääkima kassist ning läheb üle läti keelele, aga siis peatub ning tajub, et on läti keelele üle läinud, ning parandab ennast eesti keeles ja läheb taas üle läti keelele sõnaga ir 'on' ning alles siis jätkab eesti keeles.

(22) Aga meil siin tas kaķ iet un kaķ [rõhutab] (.) kass ir aga tema vist ei saa kätte.

'Aga meil siin see kass läheb ja kass kass on aga tema vist ei saa kätte'

\section{Tulemused}

Keelematerjali analüüsides selgus, et kopeerimine toimub mõlemas suunas ehk läti keelest eesti keelde ja eesti keelest läti keelde. Nagu oli oodata, on mõlema kopeerimissuuna puhul ülekaalus täielikud koopiad. Samuti on mõlemas suunas kopeeritud täielikult enamasti nimisõnu; verbe ja teisi sõnaliike on vähe. Kuigi on arvatud, et asesõnad ei ole hõlpsasti kopeeritavad, esineb siiski ühel korral ka asesõna kopeerimist. Ka kopeerimise põhjused mõlemas suunas on peaaegu samasugused. Kopeeritakse semantiliselt spetsiifilisi elemente ning materiaalselt sarnaseid elemente (ühised laenud alamsaksa keelest). Adaptsiooni puhul kopeeritakse ka sõnu, mis on seotud keelejuhi perekonnaga ja mida on harjumus kopeerida läti keelest eesti keelde. Täielikult kopeeritud nimisõnu ei integreerita alati morfosüntaktiliselt (s.o tüvele ei lisatud käändelõppe).

Diskursusmarkereid kopeeritakse mõlemas suunas. Adaptsiooni puhul (läti keelest eesti keelde) on siiski vähem pragmaatilisi sõnu. Impositsiooni puhul kopeeritakse rohkesti konjunktsioone, 
hinnangusõnu ja metakommentaare, interjektsioone. Suhtlusperformatiive ei esine kummaski kopeerimissuunas, kuna ilmselt suhtlussituatsioon ei soosinud seda. Vastavalt Matrasi (2009: 193) kontseptsioonile, mille järgi asuvad diskursus-pragmaatilised sõnad laenatavuse hierarhia tipus ning pragmaatilisi sõnu laenatakse pragmaatiliselt domineerivast keelest, mis võib olla ka sotsiolingvistiliselt domineeriv keel, võib ettevaatlikult oletada, et keelejuhi pragmaatiliselt domineeriv keel on eesti keel, kuna rohkesti kopeeritakse diskursusmarkereid just eesti keelest läti keelde.

Valikulisi koopiaid ja segakoopiaid on kordades vähem kui täielikke koopiaid. Mõlemas suunas esineb üksikuid näiteid materiaalsete ja semantiliste omaduste kopeerimise kohta. Segakoopiaid esineb vähe ning vaid impositsiooni puhul, kuid adaptsioonis ei esine ühtegi.

Mõlemas kopeerimissuunas esineb ka paar ebaselget juhtumit, mille puhul on raske määrata, mis koopialiiki need kuuluvad.

Keelejuhi kõnes esineb koodivaheldust mõlema keele suunas nii lausesiseselt kui ka lauseväliselt sageli just kellegi refereerimisel.

Nagu juba eespool kirjutasin, ei ole eesti-läti kakskeelsust siiani sünkrooniliselt uuritud, kuid seda oleks vaja rohkem uurida. Selleks oleks vaja koguda rohkem keeleainestikku ning keskenduda nii eesti-läti ja läti-eesti üksikisiku keelekasutusele kui ka segaperekondade keelekasutusele. Minu arvates võimaldaks selline kakskeelsuse uurimine teha põhjalikumaid järeldusi, milline on kakskeelse isiku keelekasutus osates kahte naaberrigi keelt.

\section{KIRJANDUS}

Backus, Ad; Verschik, Anna 2012. Copiability of (bound) morphology. Copies versus Cognates in Bound Morphology. Eds. Lars Johanson, Martine Robbeets. Boston, Leiden: BRILL Academic Publishers, 123149.

Igav, Reet 2013. Inglise-eesti koodikopeerimine Facebooki vestlustes. Magistritöö. Tallinna Ülikool.

Joenurma, Elīna 2016. Eesti-läti kakskeelse isiku keelekasutus. Magistritöö. Tallinna Ülikool. 
Johanson, Lars 1999. The Dynamics of code-copying in language encounters. - Language encounters across time and space. Eds. Bernt Brendemoen, Elizabeth Lanza and Else Ryen. Oslo: Novus Press, 39-62.

Johanson, Lars 2002. Contact-induced change in a code-copying framework. - Language change: The interplay of internal, external and extralinguistic factors. (Contribution to the Sociology of Language, 86.) Eds. Mari C. Jones, Edith Esch. Berlin, New York: Mouton de Gruyter, 285313.

Karulis, Konstantīns 1992. Latviešu etimolog̣ijas vārdnīca I. Zinātniskais red. N. Andrejevs. Rìga: Avots.

Keevallik, Leelo 2001. Tracing grammaticalization of oota 'wait' in Estonian conversation. - Papers in Estonian Cognitive Linguistics. Eds. Ilona Tragel. Tartu Ülikooli üldkeeleteaduse õppetooli toimetised 2. Tartu, 119-144.

Matras, Yaron 2009. Language contact. - Cambridge Textbooks in Linguistics. New York: Cambridge University Press.

Mela, Marjo 2007. Läti eestlased: ajalugu, keel ja kultuur. Tallinn: Eesti Keele Sihtasutus.

Mela, Marjo 2013. Eesti lätlased. Tallinn: Nornberg \& Co.

Paljasma, Veronika 2012. Prantsuse-eesti koodikopeerimine blogides. Magistritöö. Tallinna Ülikool.

Praakli, Kristiina 2009. Esimese põlvkonna Soome eestlaste kakskeelne keelekasutus ja koodikopeerimine. Doktoriväitekiri. Tartu: Tartu Ülikooli kirjastus.

Roosileht, Helin 2013. Inglise-eesti koodikopeerimine blogides. Magistritöö. Tallinna Ülikool.

Utno, Leili 2007. Eestlased Lätis I. Toim. Karl Kruus. Tallinn: Välis-Eesti.

Utno, Leili 2008. Eestlased Lätis II. Toim. Karl Kruus. Tallinn: Välis-Eesti.

Vaba, Lembit 1997. Uurimusi Läti-Eesti keelesuhetest. Tallinn-Helsinki: Eesti keele instituut/ Tampereen Yliopiston suomen kielen ja yleisen kielitieteen laitos.

Vaba, Lembit 2010a. Eestlased ja eesti keel Lätis: Liepna ja Balvi Eesti siirdlaskonna tekke-, arengu- ja hääbumislugu ühe suguvõsa perepärimuste põhjal. - Eestlased ja eesti keel välismaal. Koost ja toim Kristiina Praakli, Jüri Viikberg. Tallinn: Eesti Keele Sihtasutus, 361-381. 
Vaba, Lembit 2010b. Kuidas läti-eesti keelekontakt on mõjutanud eesti murdekeele grammatikat ja sõnamoodustust. - Emakeele Seltsi aastaraamat 56. Tallinn: Teaduste Akadeemia Kirjastus, 204-246.

Vaba, Marja 2010. Inglise-eesti koodikopeerimisest Skype’i Tallinna kontori kahe vestlusgrupi näitel. Magistritöö. Tallinna Ülikool.

Verschik, Anna 2006. Koodikopeerimise mudel: tõlgendades keelekontakte mikrotasandil. - Teoreetiline keeleteadus Eestis II. Toim Ilona Tragel, Haldur Õim. Tartu Ülikooli üldkeeleteaduse õppetooli toimetised. Tartu: Tartu Ülikooli Kirjastus, 97-111.

Verschik, Anna 2007. Keelekontaktid, laenatavus ja verbi kopeerimine eestivene keelevariandis. - Keel ja Kirjandus 5, 357-377.

Verschik, Anna 2008. Emerging Bilingual Speech: from monolingualism to code-copying. London: Continuum Publishers.

Verschik, Anna 2010. Russian-Estonian code-copying in Live Journal blogs: a preliminary overview. - Instrumentarium of Linguistics: Sociolinguistic Approaches to Non-Standard Russian. Slavica Helsingiensia 40. Eds. Arto Mustajoki, Ekaterina Protassova, Nikolai Vakhtin. Helsinki, 355-365.

Verschik, Anna 2014. Conjunctions in early Yiddish-Lithuanian Bilingualism: heritage language and contact linguistic perspectives. - Language contacts at the crossroads of disciplines. Eds. Heli Paulasto, Lea Meriläinen, Helka Riionheimo, Maria Kok. Cambridge Scholars Publishing, 33-58.

Wertheim, Suzanne 2003. Linguistic purism, language shift, and contacyinduced change in Tatar. University of California Berkeley dissertation. 